\title{
Predict the Effects of Forming Tool Characteristics on Surface Roughness of Aluminum Foil Components Formed by SPIF Using ANN and SVR
}

\author{
Sherwan Mohammed Najm ${ }^{1,2}$ (D) Imre Paniti ${ }^{3,1}$
}

Received: 29 April 2020 / Revised: 13 August 2020 / Accepted: 19 October 2020 / Published online: 13 November 2020

(c) The Author(s) 2020

\begin{abstract}
In the present work, multiple forming tests were conducted under different forming conditions by Single Point Incremental Forming (SPIF). In which surface roughness, arithmetical mean roughness (Ra) and the ten-point mean roughness (Rz) of AlMn1Mg1 sheet were experimentally measured. Also, an Artificial Neural Network (ANN) was used to predict the (Ra) and (Rz) by adopting the data collected from 108 components that were formed by SPIF. Forming tool characteristics played a key role in all the predictions and their effect on the final product surface roughness. In the aim to explore the proper materials and geometry of forming tools, different ANN structures, different training, and transfer functions have been applied to predict $(\mathrm{Ra})$ and $(\mathrm{Rz})$ as an output argument. Furthermore, Support Vector Regression (SVR) with different kernel types have been used for prediction, together with Gradient Boosting regression to sort the effective parameters on the surface roughness. The input arguments were tool materials, tool shape, tool end/corner radius, and tool surface roughness (Ra and $\mathrm{Rz}$ ). The actual data subjected to a fit regression model to generate prediction equations of $\mathrm{Ra}$ and $\mathrm{Rz}$. The results showed that ANN with one output gives the best R-Square $\left(\mathrm{R}^{2}\right)$. Levenberg-Marquardt backpropagation (Trainlm) training function recorded the highest value of $\mathrm{R}^{2}, 0.9628$ for prediction Ra using Softmax transfer function whereas 0.9972 for Rz by LogSigmoid transfer function. Furthermore, tool materials, together with tool surface (Ra), are playing a significant importance role, affecting the sheet surface roughness $(\mathrm{Ra})$. Whereas tool roughness Rz was the critical parameter effected on the Rz of the product. Also, there was a significant positive effect of tool geometry on the sheet surface roughness.
\end{abstract}

Keywords SPIF · Incremental sheet forming $\cdot$ Single point $\cdot$ ANN $\cdot$ SVR $\cdot$ Flat tool $\cdot$ Predict surface roughness $\cdot$ Aluminum alloy foils

\section{Introduction}

Conventional Sheet forming needs punch and die for shaping as stamping or deep drawing. The traditional sheet forming is useful when mass-production shares the cost of the punch

Sherwan Mohammed Najm

sherwan@manuf.bme.hu

$\bowtie$ Imre Paniti

imre.paniti@sztaki.hu

1 Department of Manufacturing Science and Engineering, Budapest University of Technology and Economics, Múegyetem rkp. 3, Budapest H-1111, Hungary

2 Kirkuk Technical Institute, Northern Technical University, Mosul, Iraq

3 Centre of Excellence in Production Informatics and Control, Institute for Computer Science and Control (SZTAKI), Kende u. 13-17, Budapest H-1111, Hungary and die, which significantly reduces the tooling costs. Small batches of production with precise geometry and the good surface finish has still been a challenge of conventional and unconventional sheet forming processes. Incremental Sheet Forming (ISF) as an unconventional method is very suitable for economical prototyping, creating customized sheet products, complex components, and non-symmetric geometries [1], even with a process variant of two synchronized tools like in [2]. A comprehensive literature review about ISF is presented in [3] about the recent developments in this field, the mechanism of the deformation by the process, modeling techniques, forming force predictions, and the investigations 
of process. Moreover, a brief review of the history of ISF focusing on technological progress is given in [4], where the reviewed articles mentioned earlier all state that ISF is suitable for economical prototyping and customized and complex sheet products. In [5], P. Shrivastava and P. Tandon investigated components formed by SPIF experimentally and analyzed them using Finite Element Analysis to understand the characteristics of sheet deformation, forming behavior, and dominant deformation mechanism. They state that ISF is a process in which capable of fulfilling the industry's demand as a highly complex, economic, and customized product. In particular, S. H. Wu et al. [6] claimed that SPIF is a process featuring flexibility in sheet forming, which lets it be capable of producing customized complex dimensional shape parts using different materials. The patent of ISF dates back to 1967, which is similar to the spinning process [4]. Since 1967 ISF developed to different concepts, mainly depending on the number of tools used at the forming process such: SPIF, TPIF, and DSIF. Therefore, industry vastly advocated the ISF in the last two decades to produce non-mass production with versatile, low cost, and higher quality. One of the most important criteria for product quality is surface roughness. S. Singh in [7] investigates the effects of seven parameters at different levels of surface roughness of Aluminum-2014 with three different thicknesses higher than $1 \mathrm{~mm}$. He found that the sheet thickness has an extreme effect on surface roughness, followed by spindle speed and lubrication. Furthermore, step size, feed rate, tool path, and tool diameter have little effect on surface roughness. Four parameters have been studied on a $1.5 \mathrm{~mm}$ thickness of PVC (polyvinylchloride) and PC (polycarbonate) by I. Bagudanch et al. [8]. They found that increasing spindle speed strongly increased surface roughness, and increased step size has less affect on increasing surface roughness. Tool diameter and feed rate have an independent effect on surface roughness. A. Mulay et al. [9] investigated the effect of feed rate, wall angle and step size on the surface roughness of $0.8 \mathrm{~mm}$ steel DC04 and aluminium alloy AA5754-H22. They reported that the most significant parameter is step size, followed by the feed rate. Moreover, they observed that an increasing formed depth increased the average surface roughness of the components and vitally increased due to increasing step size. Also, the increment of feed rate conduces increment of the average surface roughness. V. Gulati et al. in [10] experienced six different parameters on surface roughness of the formed components of Aluminum 6063, having different thickness higher than $0.5 \mathrm{~mm}$. They concluded that decrementing tool rotational speed, sheet thickness, feed rate, and step depth resulted in decreasing surface roughness and increase with a decrease in tool radius. Lubrication greatly affected the surface roughness compared to a dry process, so they used coolant lubricant for forming. Four process parameters have been investigated by S. A. Nama et al. [11].
They found that the surface roughness decreases in $0.6 \mathrm{~mm}$ Aluminum 1100 sheets by increasing tool tip diameter, tool rotation speed, and feed rate. Besides that, the grease gave less surface roughness when compared with coolant oil in all cases. Effective speed on DIN 1.0037 steel was studied by K. Rattanachan and C. Chungchoo [12]. They claimed that the increase of roughness and wear of components due to increased tool rotational speed led to decreased formability. According to D. H. Nimbalkar and V. M. Nandedkar review [13], the main element in a single point incremental process is the tool. Because forming tools are not available in markets as a part of an assortment made, thus a used tool, which usually is a hemispherical tool, was designed and manufactured by researchers. A review article pointed out the effect of forming tools and other process parameters on surface roughness in ISF [14]. They observed 89 publications from 2000-2005, 457 from 2005-2010, 1490 from 2010-2015, and 829 from 2015-2017. However, they claimed that publishing would be rising in the coming years. They said that "Presently no papers have been found that investigate specifically the influence of tool materials on roughness." In their survey, 20 articles referred to the effects of forming tool size (in the range of $2.5-25 \mathrm{~mm}$ ) on surface roughness. Moreover, five papers were studied with a different sheet thickness (between 0.55 and $2.54 \mathrm{~mm}$ ) on surface roughness. Recently ANNs are implemented to develop prediction models in the field of metallurgy, end milling and high-speed machining [15-17]. In the last decade, the most useful predictive models for developing manufacturing was machine learning [18-22]. Furthermore, there are different optimization algorithms commonly used in the manufacturing process. For example, the Johnson-Cook model constants (J-C constants) of ultra-fine-grained titanium were determined by J. Ning et al. [23]. The J-C constants identified via enforcing the gradient search method using a Kalman Filter based on the chip formation model. Therefore, by utilizing the defined $\mathrm{J}-\mathrm{C}$ constants, the machining forces were foretold under various cutting conditions and compared to the forces of corresponding experimental. They found close agreements between predicted forces and experimental forces. J. Ning and S. Y. Liang [24] developed the inverse identification method for J-C constants by replacing the exhaustive search method with an iterative gradient search method based on the Kalman filter algorithm. They predicted the machining forces by the modified chip formation model and the J-C constants, where they identified using an iterative gradient search method when the minimal difference between predicted forces and the experimental forces was obtained. Zuo et al. [25] presented a new approach to reduce the design space and to guarantee the topology outcome in terms of manufacturability and accepted engineering. The approach was introducing manufacturing and machining constraints to the topology optimization method formula. Therefore, 
modified topology optimization has been capable of solving nonmanufacturing and non-machining problems in engineering applications. Maji and Kumar [26] found that the adaptive neuro-fuzzy inference system (ANFIS) has more accurate prediction using a hybrid algorithm than using a Back-propagation algorithm. They developed Response surface methodology and ANFIS to predict the outcome of SPIF components considering different process parameters and inverse predictions of the process parameters in SPIF. Furthermore, they have utilized desirability function and a non-dominated sorting genetic algorithm for performing multi-objective optimization in SPIF.

Researchers Modeled and optimized different parameters in a SPIF process using an artificial neural network. In [27], S. Kurra et al. focused and developed models to predict the surface roughness of the SPIF. The used inputs were tool diameter, vertical step, wall angle, feed rate, and lubricant. M. Oraon and V. Sharma, in [28], used the Model of ANN to predict the quality of the SPIF component surface. The inputs were step size, feed rate, spindle speed, sheet thickness, wall angle, and density of lubricant. C. Radu et al. prescribed the accuracy of the component of SPIF by utilizing the ANN model. Tool diameter, feed rate, step depth, and spindle speed used as input [29]. In [30], tool diameter, sheet thickness, feed rate, and step depth were used as input in a developed ANN model to predict average surface roughness and the wall angle of AA5052-H3 SPIF components. In [31], feed-forward backpropagation (FFBP) used to predict surface roughness of brass Cu67Zn33 manufactured by the SPIF process. The developed ANN structure was 6-6-1.

Based on the literature review, until now no investigation in SPIF has been done to study the effect of tool materials on surface roughness, no experiments found to studying the surface roughness on a sheet of thickness lower than $0.5 \mathrm{~mm}$, and no perusal carried out to investigate the effect of a tiny corner radius of a flat forming tool on the surface roughness. Thus, the objective of this study is the examination of some process parameters on formed component surface roughness experimentally in the previously mentioned conditions and making predictions on Ra and Rz values by ANN and SVR. Furthermore, the effect of forming tool tip surface roughness on the surface roughness of the formed sheet is also investigated.

\section{Material Properties}

In this study, steel (C45), Brass (CuZn39Pb3), Bronze (CuSn12), copper (E-Cu57), Aluminum AlMgSi 0,5 and polymer VeroWhitePlus, RGD835 were utilized as forming tool material in all experiments (See Fig. 1). The tool scheme is shown in Fig. 2, where a different corner radius ( $\mathrm{r}$ ) for the flat tool and different radius ( $\mathrm{R}$ ) for the

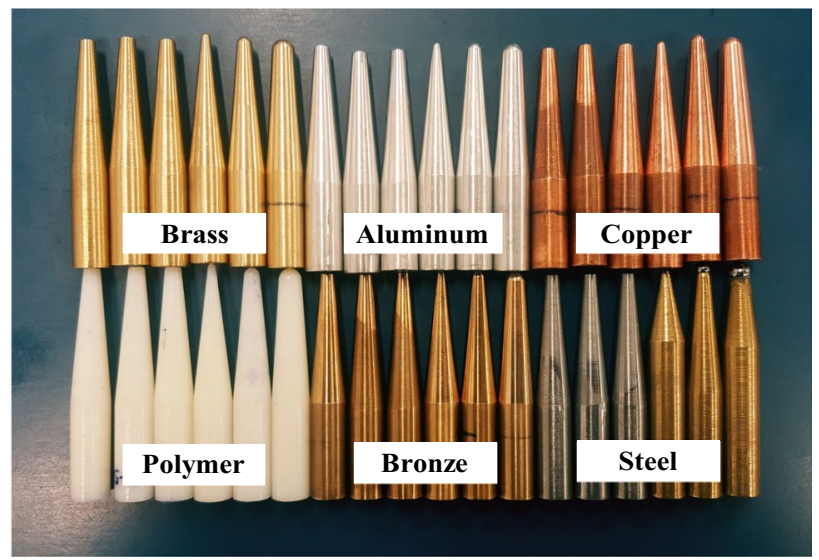

Fig. 1 Tool materials

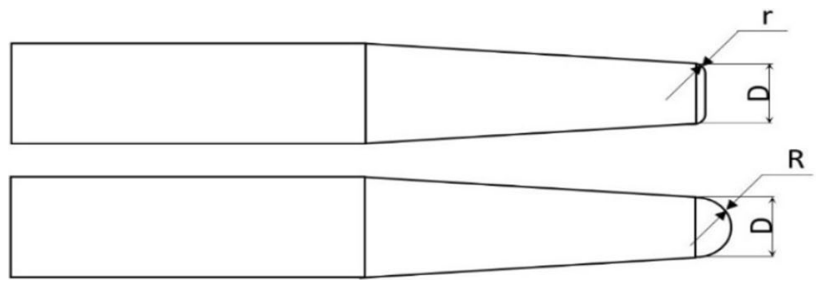

Fig. 2 Tool scheme

hemispherical tool was used. The (r) values are $0.1 \mathrm{~mm}$, $0.3 \mathrm{~mm}$, and $0.5 \mathrm{~mm}$, while the (R) values are $2 \mathrm{~mm}$, $4 \mathrm{~mm}$, and $6 \mathrm{~mm}$. The hardness of the tools has been tested experimentally by Wolpert Diatronic 2RC S hardness tester, and the measurement was carried out based on ISO 6506-1:2014. The materials were measured by FOUNDRY-MASTER Pro2 Optical Emission Spectrometer to determine the ISO code of each type of tool material. Using the ISO code of each material, the chemical composition and the mechanical properties were listed in Tables 1 and 2, respectively. The sources of the properties are provided by measurements from [SAARSTAHL, L. KLEIN SA, AURUBIS, PX PRECIMET SA, ALUMINCO S.A.] based on the sequence of the materials in the mentioned tables. The properties of the polymer's tip shown in Table 3 are provided by STRATASYS. AlM$\mathrm{n} 1 \mathrm{Mg} 1$ aluminum alloy has been used in the present investigation, and the chemical compositions blank material has been displayed in Table 4 . By cutting the specimens from the sheet at $0^{\circ}, 45^{\circ}$, and $90^{\circ}$ of the rolling directions, tensile tests were carried out at room temperature on the INSTRON 5582 universal testing machine. The tensile tests had been done based on EN ISO 6892- 1:2010 standard. Advanced Video Extensometer (AVE) used to measure the planar anisotropy values (r10). The mechanical properties are tabulated in Table 5. 
Table 1 Tools material chemical composition

\begin{tabular}{|c|c|c|c|c|c|c|c|c|c|c|}
\hline \multirow{2}{*}{$\begin{array}{l}\text { Material } \\
\text { Steel }\end{array}$} & \multicolumn{10}{|l|}{ wt $\%$} \\
\hline & $\mathrm{C}$ & $\mathrm{Si}$ & Mn & $\mathrm{P}$ & $\mathrm{S}$ & & $\mathrm{Cr}$ & Mo & $\mathrm{Ni}$ & $\mathrm{Cr}+\mathrm{Mo}+\mathrm{Ni}$ \\
\hline C45 & $0.42-0.50$ & $<0.40$ & $0.50-0.80$ & $<0.045$ & $<0.045$ & & $<0.40$ & $<0.10$ & 0.40 & $<0.63$ \\
\hline \multirow[t]{2}{*}{ Brass (CuZn39Pb3) } & $\mathrm{Cu}$ & $\mathrm{Fe}$ & $\mathrm{Ni}$ & $\mathrm{Pb}$ & $\mathrm{Sn}$ & $\mathrm{Al}$ & & & Others & $\mathrm{Zn}$ \\
\hline & $57-59$ & 0.5 & 0.3 & $2.5-3.5$ & 0.3 & 0.005 & & & 0.2 & Rest \\
\hline \multirow[t]{2}{*}{ Bronze (CuSn8) } & $\mathrm{Sn}$ & $\mathrm{Fe}$ & $\mathrm{Ni}$ & $\mathrm{Pb}$ & $\mathrm{Zn}$ & $\mathrm{P}$ & & & & $\mathrm{Cu}$ \\
\hline & $7.5-8.5$ & 0.1 & 0.2 & 0.02 & 0.2 & $0.01-0.4$ & & & & Rest \\
\hline \multirow[t]{2}{*}{ Copper (E-Cu57) } & $\mathrm{O}$ & & & & & & & Others & & $\mathrm{Cu}$ \\
\hline & 0.04 & & & & & & & 0.06 & & Rest \\
\hline \multirow[t]{2}{*}{ Aluminum AlMgSi 0.5} & $\mathrm{Si}$ & $\mathrm{Fe}$ & $\mathrm{Cu}$ & Mn & $\mathrm{Zn}$ & $\mathrm{Cr}$ & $\mathrm{Mg}$ & $\mathrm{Ti}+\mathrm{Zr}$ & Others & $\mathrm{Al}$ \\
\hline & $0.3-0.6$ & $0.1-0.3$ & 0.1 & 0.1 & 0.15 & 0.05 & $0.35-0.6$ & 0.1 & $0.05-0.15$ & Rest \\
\hline
\end{tabular}

Table 2 Tools mechanical properties

\begin{tabular}{llll}
\hline Material & $\begin{array}{l}\text { Tensile } \\
\text { strength } \\
\text { Rm MPa }\end{array}$ & $\begin{array}{l}\text { Yield strength } \\
\text { Rp 0.2 MPa }\end{array}$ & $\begin{array}{l}\text { Brinell } \\
\text { hard- } \\
\text { ness } \\
\text { HB }\end{array}$ \\
\hline Steel (C45) & 700 & 490 & 223 \\
Brass (CuZn39Pb3) & 500 & 390 & 186 \\
Bronze (CuSn8) & 450 & 300 & 135 \\
Copper (E-Cu57) & 395 & 365 & 88 \\
Aluminum (AlMgSi 0.5) & 215 & 160 & 73 \\
\hline
\end{tabular}

Table 3 Polymer properties

\begin{tabular}{llllll}
\hline Polymer & $\begin{array}{l}\text { Density } \\
\left(\mathrm{g} / \mathrm{cm}^{3}\right)\end{array}$ & $\begin{array}{l}\text { Elastic } \\
\text { modulus } \\
(\mathrm{MPa})\end{array}$ & $\begin{array}{l}\text { Tensile } \\
\text { strength } \\
(\mathrm{MPa})\end{array}$ & $\begin{array}{l}\text { Elonga- } \\
\text { tion at } \\
\text { break \% }\end{array}$ & $\begin{array}{l}\text { Shore D } \\
\text { hardness }\end{array}$ \\
\hline $\begin{array}{l}\text { VeroW- } \\
\text { hitePlus, }\end{array}$ & 1.19 & 2500 & 58 & 25 & 85 \\
\begin{tabular}{l} 
RGD835 \\
\hline
\end{tabular} & & & & & \\
\hline
\end{tabular}

\section{Experiments}

To clarify the experimental work, the aims of this study have been listed below:

- Inspect the effect of different tool materials on the formed sheet surface roughness by SPIF.

- Examine the effect of the tool tip roughness on the roughness of the formed sheet.

- Determination of the differences in term of formed sheet surface roughness due to tool shape change.

- Investigate the variance of formed sheet surface roughness by different tool diameters.

- Implement all experimental data on machine learning models to predict the Roughness value.

- Compare different models and different functions based on the coefficient of determination (R-Square) and adjusted R-Square.

- Detect effective parameters on the surface roughness with Gradient Boosting Regression [32], see Sect. 4.3.
Table 4 Blank material chemical composition

Table 5 Blank material mechanical properties

\begin{tabular}{llllllllll}
\hline $\mathrm{Al}$ & $\mathrm{Si}$ & $\mathrm{Fe}$ & $\mathrm{Cu}$ & $\mathrm{Mn}$ & $\mathrm{Mg}$ & $\mathrm{Zn}$ & $\mathrm{Cr}$ & $\mathrm{Ni}$ & Others \\
\hline 96.90 & 0.201 & 0.448 & 0.212 & 0.807 & 1.260 & 0.071 & 0.022 & 0.006 & 0.073 \\
\hline
\end{tabular}

\begin{tabular}{lllllll}
\hline Direction & $\begin{array}{l}\text { Yield strength } \\
(\mathrm{MPa})\end{array}$ & $\begin{array}{l}\text { Ultimate tensile } \\
\text { strength (MPa) }\end{array}$ & Elongation (\%) & $\begin{array}{l}\text { Elongation } \\
\text { A50 }(\%)\end{array}$ & $\mathrm{n} 5$ & $\mathrm{r} 10$ \\
\hline $0^{0}$ & 88.3 & 183.0 & 16.44 & 16.88 & 0.297 & 0.554 \\
$45^{0}$ & 90.0 & 155.5 & 9.27 & 10.45 & 0.266 & 0.580 \\
$90^{0}$ & 86.3 & 170.3 & 12.48 & 12.95 & 0.268 & 0.594 \\
\hline
\end{tabular}




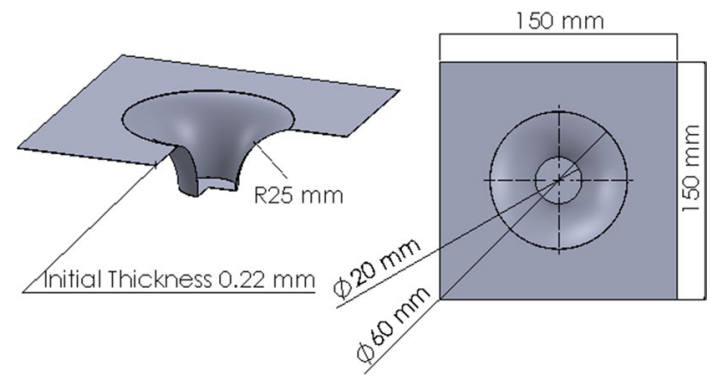

Fig. 3 Frustum geometry

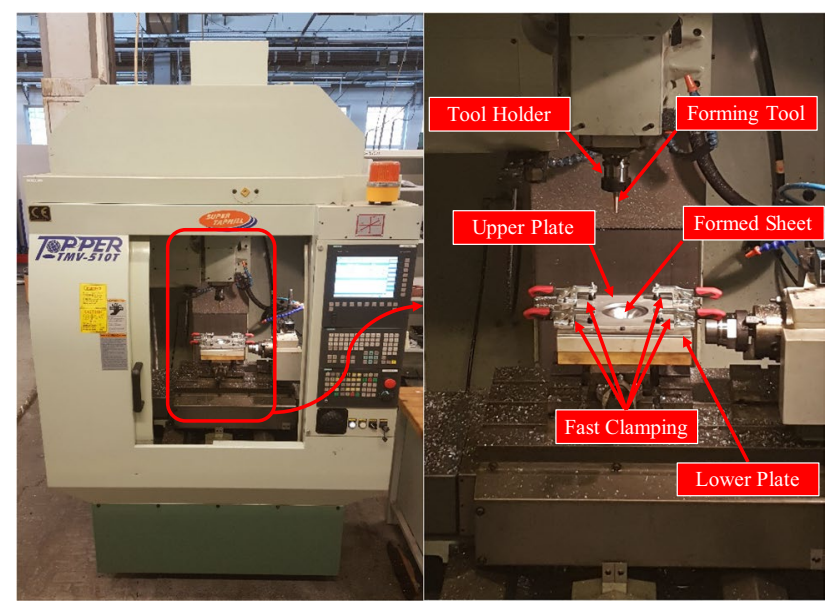

Fig. 4 SIEMENS Topper CNC and Experimental setup

Table 6 Fixed process parameters

\begin{tabular}{lllll}
\hline $\begin{array}{l}\text { Path strat- } \\
\text { egy }\end{array}$ & $\begin{array}{l}\text { Feed rate } \\
(\mathrm{mm} / \mathrm{min})\end{array}$ & $\begin{array}{l}\text { Spindle } \\
\text { speed }(\mathrm{rpm})\end{array}$ & $\begin{array}{l}\text { Step down } \\
(\mathrm{mm})\end{array}$ & Lubricant \\
\hline Helical & 1500 & 2000 & 0.05 & Machine oil \\
\hline
\end{tabular}

Frustum cones, as shown in Fig. 3, were formed from the blanks having a thickness of $0.22 \mathrm{~mm}$ and a size of $150 \mathrm{~mm} \times 150 \mathrm{~mm}$. Experiments were performed on SIEMENS Topper TMV-510T 4-axis CNC milling machine with sinumerik 840-D controller. The machine and the experimental setup of SPIF are shown in Fig. 4. The other process parameters were fixed, as shown in Table 6. Once the components were formed, the roughness was measured by Mitutoyo SJ.400, as shown in Fig. 5. To increase the reliability of measures, each sample was formed three times experimentally. The total number of the formed components was 108. The data collected from these samples have been used as an actual dataset (input and output) for prediction purposes: considering the process parameters as inputs and the measured surface roughness of the formed sheet as outputs. The measurement direction of the surface roughness is

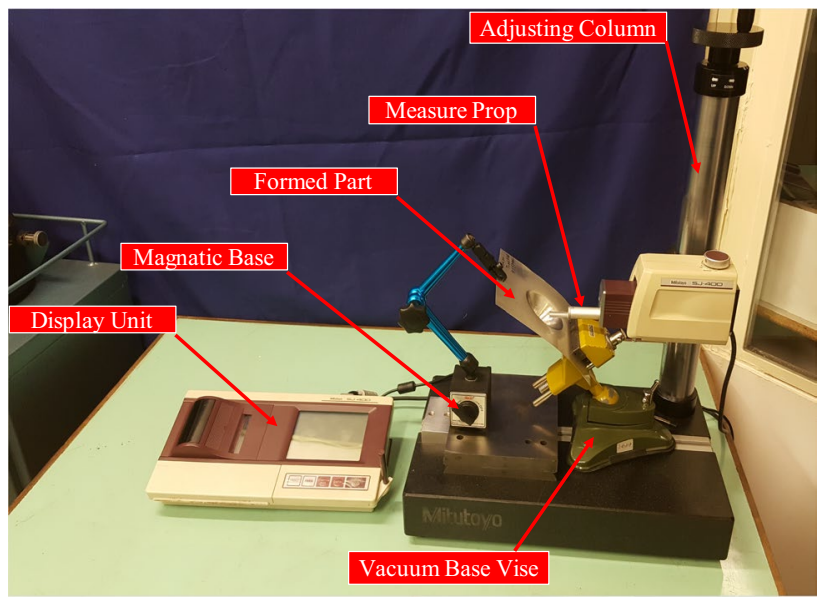

Fig. 5 Mitutoyo SJ.400 surface roughness measurement

along to the forming depth, and the average surface roughness was taken from the inner surface of the parts. In each forming process, the surface roughness of the tool surface has been measured before and after the forming. The value of the surface roughness of the forming tool before the forming process is the adopted input value of the formed product. As for the value tool surface roughness after the forming process, it was taken for the subsequent forming process and so on. This method has been applied to all used tools in this research. Nevertheless, due to the wear on the polymer tool surface caused by the forming, a new polymer-forming tool was used in each forming process, and each polymer tool surface roughness has been measured before starting the process.

\section{Predictive models}

In this section, different methods like Artificial Neural Networks (ANN), Support Vector Regression (SVR), and Gradient Boosting Regression (GBR) will be introduced for prediction.

\subsection{Artificial Neural Networks (ANN)}

In the present study, ANN was modeled to predict the Surface roughness ( $\mathrm{Ra}$ and $\mathrm{Rz}$ ) of SPIF components using different structures, different training, and transfer functions. Training, testing, and validation are applied to the networks by using MATLAB ANN toolbox. Two network structures are built consisting of input, hidden, and output layers, and the number of neurons is (5-10-2, or 5-10-1), respectively, as shown in Fig. 6a, b. Tool materials, tool shape, tool end corner radius, and tool surface roughness $(\mathrm{Ra} / \mathrm{Rz})$ used in the five neurons of the input layer. The tools were classified into 

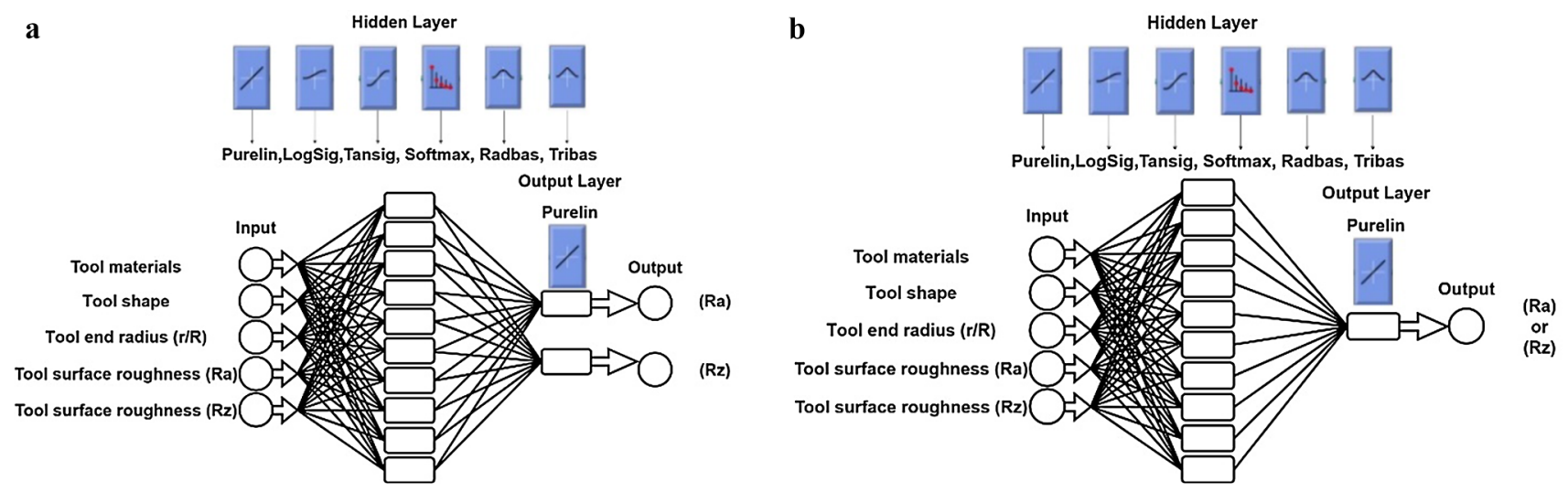

Fig. 6 ANN structures modelling of SPIF. (a) Two outputs, (b) One output

two groups based on their shapes (Flat and Hemispherical) to check the effect of tool shape on surface roughness ( $\mathrm{Ra}$ and $\mathrm{Rz}$ ). Furthermore, each shape was divided into three sections based on the corner radius values ( $r$ ) for flat tool and the tip radius values $(\mathrm{R})$ for the Hemispherical tool in order to assess the effectiveness of these factors on the sheet roughness. Ten neurons are implemented in one hidden layer, and the main difference between the structures is the number and types of output arguments ( $\mathrm{Ra}$ and $\mathrm{Rz}$ together, $\mathrm{Ra}$ as a single output, and $\mathrm{Rz}$ as a single output) at the output layer.

\subsubsection{Training and Transfer function}

Three different training functions with six different transfer functions have been run to map the output parameters. The training functions are Levenberg-Marquardt backpropagation (Trainlm), Conjugate gradient backpropagation with Powell-Beale restarts (Traincgb), and Resilient backpropagation (Trainrp). In each of the training functions, different transfer functions applied individually at the hidden layer. The transfer functions are Linear transfer function, Log-Sigmoid, Tan-Sigmoid, Softmax, Radial basis, and Triangular basis. Finally, Purelin function is used in the output layer for all running.

\subsubsection{Distribution of dataset}

ANN is capable of predicting the results of the forming process, which can estimate the output based on the historical data of inputs without a new forming process. Based on a survey paper of ANN applications in predicting [33], the performance of the ANN model affected by the dividing data to train and test sets. One of the dividing problems is the number of data in (training and test) 's dataset, and there is no general setting to solve this problem. Inappropriate dividing datasets affected negatively on

the prediction performance. Based on the literature, most researchers divide their datasets, adopting training versus testing as $90 \%$ with $10 \%, 80 \%$ with $20 \%$, or $70 \%$ with $30 \%$. For our structure, the optimal results were achieved by $80 \%$ of the actual data (108 experiments) for training and $20 \%$ stored for testing. $90 \%$ of $80 \%$ of the dataset used for training, 5\% for validation, and 5\% for testing. In other words, 86 datasets ("rows") from the actual data have been used for training, and 22 rows of them are used to test the network. All other ANN control parameters are listed in Table 7.

\subsection{Support Vector Regression (SVR)}

Support Vector Regression is an extension of the concept of Support Vector Machine SVM. SVM is developed by Vapnik et al., where a nonlinear function builds a relationship between the input and output of the training dataset. Parrella [34], developed an online toolbox for SVR and used it in this present paper to model the SPIF. The same data size used in ANN (80\% training via $20 \%$ testing) has been adopted for SVR. The training data set was executed twice individually with different outputs ( $\mathrm{Ra}$ and $\mathrm{Rz}$ ). Four different kernels have been used as a kernel type in each running to predict the ( $\mathrm{Ra}$ and $\mathrm{Rz}$ ). The kernel types are Radial basis function (RBF), Gaussian (RBF), Linear, and Exponential (RBF). In this research, the SVR toolbox has been implemented with 30 kernel parameters, and the $\varepsilon$

Table 7 ANN Control parameters

\begin{tabular}{ll}
\hline ANN parameters & \\
\hline Learning rate & 0.01 \\
Performance goal & 0.001 \\
Number of epochs & 1000 \\
Number of hidden layers & 1 \\
\hline
\end{tabular}




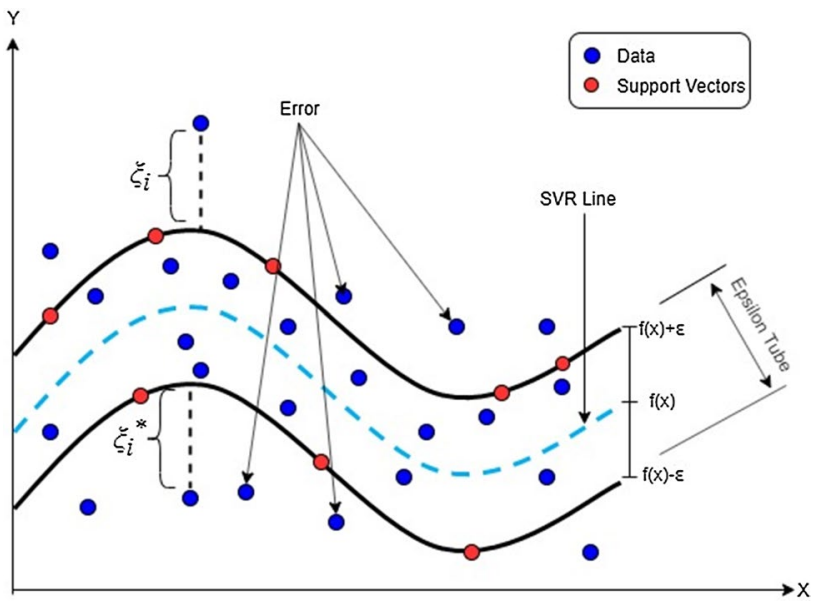

Fig. 7 Support Vector regression

value is 0.001 , which $\varepsilon$ value is the epsilon tube size illustrated in Fig. 7.

The following equations can be used for prediction in Support Vector regression [27].

$f(x)=w^{T} \cdot \varnothing(x)+b$

where $w^{T}$ is the transposed version of the weight vector $w$, $\mathrm{b}$ is the bias, and $\varnothing(x)$ is the kernel function. The goal is to find a function $f(\mathrm{x})$, which must be as flat as much as can by finding the smallest $w$, to deny the overfitting. To increase the machine tolerance slack -variables $\left(\xi_{i}\right.$ and $\left.\xi_{i}^{*}\right)$ should be added to the function of minimum weight $w$ as shown in equation 2 and 3 . $\left(\xi_{i}\right.$ and $\left.\xi_{i}^{*}\right)$ is equal to zero inside the epsilon tube, and increase based on the error point outside the tube.

$\min _{w, b} \frac{1}{2} w^{T} \cdot w+C \sum_{i=1}^{l}\left(\xi_{i}+\xi_{i}^{*}\right)$

where $C$ is a constant to determine the trade-off the largest deviations.

Equation (2) with the output subjected to the following:

$y_{i}-\left(w^{T} \cdot \varnothing(x)+b\right) \leq \varepsilon+\xi_{i}$

$\left(w^{T} \cdot \varnothing(x)+b\right)-y_{i} \leq \varepsilon+\xi_{i}^{*}$

$\left(\xi_{i}+\xi_{i}^{*}\right)$ are $\geq 0$, any data above the $\varepsilon$ will be captured in $\xi_{i}$ and any data that is below the $\varepsilon$ will be captured in $\xi_{i}^{*}$. The definition of this $\varepsilon$-insensitive loss function is as follows:

$|\xi|_{\varepsilon}=0 ; \quad$ if $\quad|f(x)-y|<\varepsilon$

$|f(x)-y|-\varepsilon ;$ otherwise

\subsection{Gradient Boosting Regression (GBR)}

Regression with Boosted Decision Trees is used to determine the regression of SPIF parameters on the expected output of surface roughness ( $\mathrm{Ra}$ and $\mathrm{Rz}$ ) based on their effects. Boost technique is sequentially learning the learners with previously learners that fitted to the data and analyzing the errors. In the present paper, the Gradient Boosting Regression code [32] is implemented. Five MinLeaf applied for the regression tree and 500 Ensemble Members to increase the efficiency of the predictions because shallow trees are used in boost algorithms usually. MinLeaf is the number of leaf node observations. Each leaf has at least MinLeaf observations over a tree leaf. Least-squares boosting algorithm (LSBoost) used to train an ensemble of regression trees. LSBoost is an algorithm to create regression ensembles to minimize mean-squared error MSE. Minimizing the MSE is by finding the difference between the observed response and the aggregated prediction of all learners trained before, and fits a new learner to the difference [35].

\section{Results and discussion}

Two different models are developed to estimate the surface roughness ( $\mathrm{Ra}$ and $\mathrm{Rz}$ ) of the components. Boosted Decision Trees are used for regression and to detect the effective SPIF parameter on the values of $\mathrm{Ra}$ and $\mathrm{Rz}$ of the components. Divers transfer functions were trained with different training functions to find the optimal ANN. All the model results with different ANN structures and different kernel types validated based on the correlation coefficient R-Square and Mean Square Error MSE values. Table 8 lists the $\mathrm{R}^{2}$ and MSE for the first structure $(5,10,2)$ and different training and transfer functions with their results for all datasets.

Generally, the results of two output structures show that the Trainlm output is better than Traincgb and Trainrp; also, Traincgb is better than Trainrp. The highest prediction was given by using Trainlm training function with a Softmax transfer function, which the $\mathrm{R}^{2}$ values are 0.9236 and 0.9922 for Ra and Rz, respectively. Furthermore, higher values of $\mathrm{R}^{2}$ results from Traincgb training function adopting Radbas transfer function 0.9174 via 0.9858 for $\mathrm{Ra}$ and $\mathrm{Rz}$, respectively. For Trainrp training function, Logsig transfer function recorded a higher $\mathrm{R}^{2}$ value of $\mathrm{Ra}$ and $\mathrm{Rz}$ by 0.8893 and 0.9757 , respectively.

The second and third structures have the same architecture $(5,10,1)$ with different outputs. The second structure has $\mathrm{Ra}$ as an output and the third one mapping $\mathrm{Rz}$ as an output. Table 9 shows the results of these two structures based on different training functions and six transfer functions.

ANN structure with one output recorded a better prediction of $\mathrm{Ra}$ in all cases than the structure of two outputs. 
Table $8 \mathrm{R}^{2}$ and MSE for the first structure $(5,10,2)$ with different training and transfer functions

\begin{tabular}{|c|c|c|c|c|c|c|c|c|c|c|c|c|}
\hline \multirow{3}{*}{$\begin{array}{l}\text { Training function } \\
\text { Transfer function }\end{array}$} & \multicolumn{12}{|c|}{ ANN 2 Output Ra and Rz } \\
\hline & \multicolumn{12}{|c|}{ Levenberg-Marquardt backpropagation (Trainlm) } \\
\hline & \multicolumn{2}{|l|}{ Purlin } & \multicolumn{2}{|l|}{ Logsig } & \multicolumn{2}{|l|}{ Tansig } & \multicolumn{2}{|l|}{ Softmax } & \multicolumn{2}{|l|}{ Radbas } & \multicolumn{2}{|l|}{ Tribas } \\
\hline Response & $\mathrm{Ra}$ & $\mathrm{Rz}$ & $\mathrm{Ra}$ & $\mathrm{Rz}$ & $\mathrm{Ra}$ & $\mathrm{Rz}$ & $\mathrm{Ra}$ & $\mathrm{Rz}$ & $\mathrm{Ra}$ & $\mathrm{Rz}$ & $\mathrm{Ra}$ & $\mathrm{Rz}$ \\
\hline $\mathrm{R}^{2} \%$ & 0.5556 & 0.6410 & 0.8969 & 0.9464 & 0.9066 & 0.9796 & 0.9236 & 0.9922 & 0.9238 & 0.9906 & 0.8969 & 0.9756 \\
\hline MSE & 0.00428 & 0.19112 & 0.00125 & 0.04185 & 0.00108 & 0.01472 & 0.00102 & 0.00622 & 0.00097 & 0.00759 & 0.00114 & 0.01503 \\
\hline Training function & \multicolumn{12}{|c|}{ Conjugate gradient backpropagation with Powell-Beale restarts (Traincgb) } \\
\hline $\mathrm{R}^{2} \%$ & 0.6250 & 0.6002 & 0.8948 & 0.9723 & 0.9030 & 0.9756 & 0.8701 & 0.9417 & 0.9174 & 0.9858 & 0.8692 & 0.9173 \\
\hline MSE & 0.00345 & 0.34116 & 0.00133 & 0.02408 & 0.00135 & 0.01899 & 0.00157 & 0.04490 & 0.00105 & 0.01272 & 0.00175 & 0.05422 \\
\hline Training function & \multicolumn{12}{|c|}{ Resilient backpropagation (Trainrp) } \\
\hline $\mathrm{R}^{2} \%$ & 0.6270 & 0.6228 & 0.8893 & 0.9757 & 0.8558 & 0.9702 & 0.8825 & 0.9564 & 0.8439 & 0.9708 & 0.8279 & 0.8915 \\
\hline MSE & 0.00344 & 0.19207 & 0.00142 & 0.01908 & 0.00168 & 0.02301 & 0.00151 & 0.03862 & 0.00195 & 0.02366 & 0.00206 & 0.07990 \\
\hline
\end{tabular}

Table $9 \mathrm{R}^{2}$ and MSE for the second and third structures $(5,10,1)$ with different training and transfer functions

\begin{tabular}{|c|c|c|c|c|c|c|c|c|c|c|c|c|}
\hline \multirow{3}{*}{$\begin{array}{l}\text { Training function } \\
\text { Transfer function }\end{array}$} & \multicolumn{12}{|c|}{ ANN 1 Output Ra or Rz } \\
\hline & \multicolumn{12}{|c|}{ Levenberg-Marquardt backpropagation (Trainlm) } \\
\hline & \multicolumn{2}{|l|}{ Purlin } & \multicolumn{2}{|l|}{ Logsig } & \multicolumn{2}{|l|}{ Tansig } & \multicolumn{2}{|l|}{ Softmax } & \multicolumn{2}{|l|}{ Radbas } & \multicolumn{2}{|l|}{ Tribas } \\
\hline Response & $\mathrm{Ra}$ & $\mathrm{Rz}$ & $\mathrm{Ra}$ & $\mathrm{Rz}$ & $\mathrm{Ra}$ & $\mathrm{Rz}$ & $\mathrm{Ra}$ & $\mathrm{Rz}$ & $\mathrm{Ra}$ & $\mathrm{Rz}$ & $\mathrm{Ra}$ & $\mathrm{Rz}$ \\
\hline $\mathrm{R}^{2} \%$ & 0.6143 & 0.6363 & 0.9391 & 0.9972 & 0.9581 & 0.9942 & 0.9628 & 0.9846 & 0.9527 & 0.9827 & 0.9443 & 0.9265 \\
\hline MSE & 0.00344 & 0.18506 & 0.00082 & 0.00224 & 0.00054 & 0.00408 & 0.00044 & 0.01254 & 0.00060 & 0.01349 & 0.00070 & 0.05864 \\
\hline Training function & \multicolumn{12}{|c|}{ Conjugate gradient backpropagation with Powell-Beale restarts (Traincgb) } \\
\hline $\mathrm{R}^{2} \%$ & 0.6371 & 0.6447 & 0.9447 & 0.9852 & 0.9549 & 0.9865 & 0.9494 & 0.9661 & 0.9528 & 0.9871 & 0.9477 & 0.9316 \\
\hline MSE & 0.00332 & 0.19162 & 0.00072 & 0.01206 & 0.00065 & 0.01083 & 0.00060 & 0.02688 & 0.00063 & 0.01140 & 0.00068 & 0.05471 \\
\hline Training function & \multicolumn{12}{|c|}{ Resilient backpropagation (Trainrp) } \\
\hline $\mathrm{R}^{2} \%$ & 0.6335 & 0.6157 & 0.9545 & 0.9821 & 0.9552 & 0.9809 & 0.9345 & 0.9778 & 0.9434 & 0.9830 & 0.9403 & 0.9422 \\
\hline MSE & 0.00334 & 0.19087 & 0.00059 & 0.01496 & 0.00061 & 0.01548 & 0.00079 & 0.01735 & 0.00067 & 0.01405 & 0.00077 & 0.04532 \\
\hline
\end{tabular}

Generally, the Trainlm function of two output structures has better results in the prediction of $\mathrm{Rz}$ in spite of the highest value of $\mathrm{R}^{2}$ of $\mathrm{Rz}$ obtained via one structure using Logsig. One output structure showed high values in $\mathrm{R}^{2}$ using Traincgb or Trainrp training function except for small differences in $\mathrm{R}^{2}(0.0071)$ using purelin transfer function with Trainrp in favor of the two output structure.

Again, the results of predicting using one argument in the output of the ANN structures show that the Trainlm output is better than Traincgb and Trainrp in both Ra and Rz; but this time Trainrp recorded better results than Traincgb. The highest value of predicted $\mathrm{Ra}(0.9628)$ achieved by Trainlm with Softmax, and Trainlm with Logsig for $\mathrm{Rz}$ (0.9972). Tansig and Radbas showed the best value for $\mathrm{Ra}(0.9549)$ and (0.9552), and $\mathrm{Rz}(0.9871)$ and (0.9830) by implementing Traincgb or Trainrp as training function, respectively. Figure 8 shows the variation between the Actual data of the best ( $\mathrm{Ra}$ and $\mathrm{Rz}$ ) obtained from the SPIF experiments and the predicted values with two used ANN models for surface roughness in SPIF.
Table 10 shows the results of the prediction based on the list of different kernels adopted in the SVR model. Radial basis function shows the highest value of $\mathrm{R}^{2}$ than the other kernel to predict $\mathrm{Ra}$ and $\mathrm{Rz}$. Even though there are only slight differences between the prediction results of the ANN and the SVR, comparing the two results, it can be seen that the prediction from the ANN is more accurate than the SVR. Furthermore, after splitting the data into training and testing datasets, the single most striking observation to emerge from the result is that the prediction of test data by SVR is sharply inaccurate than the training data prediction. Table 11 shows the results obtained from the analysis of the predicted $\mathrm{Ra}$ and Rz using SVR with RBF kernel.

Due to the poor prediction in test results using SVR, as shown in Fig. 9, this paper has focused on ANN analysis more than SVR.

Based on the result ANN of one structure that used Trainlim training function showed the best result, Softmax transfer function to predict Ra and Logsig transfer function for estimate Rz. Table 12 shows more details for these two 


\section{Actual $R a$ and $R z$ vs ANN Prediction}
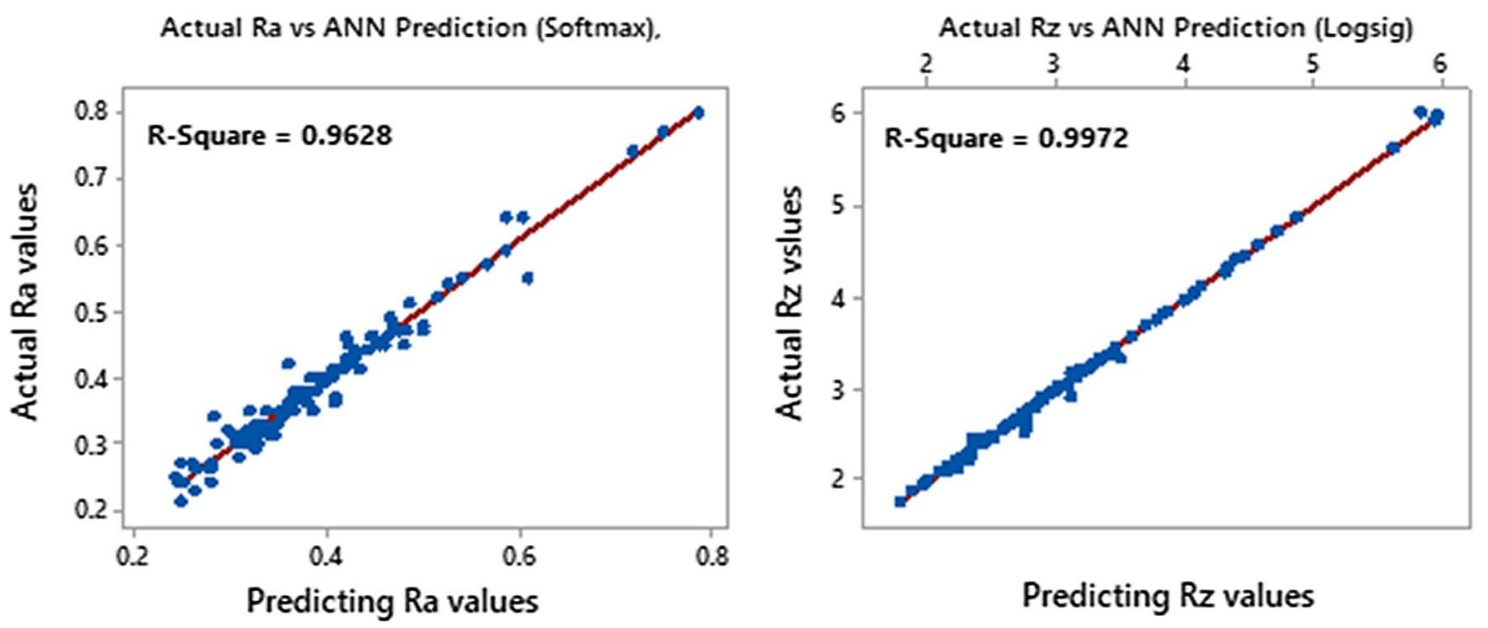

Fig. 8 Actual and predicted values of Ra and Rz

Table $10 \mathrm{R}^{2}$ and MSE for SVR Model with different kernels

\begin{tabular}{|c|c|c|c|c|c|c|c|c|}
\hline \multirow{3}{*}{$\begin{array}{l}\text { Model } \\
\text { Kernel } \\
\text { Response }\end{array}$} & \multicolumn{8}{|l|}{ SVR } \\
\hline & \multicolumn{2}{|l|}{ RBF } & \multicolumn{2}{|c|}{ Gaussian-RBF } & \multicolumn{2}{|l|}{ Linear } & \multicolumn{2}{|c|}{ Exponential-RBF } \\
\hline & $\mathrm{Ra}$ & $\mathrm{Rz}$ & $\mathrm{Ra}$ & $\mathrm{Rz}$ & $\mathrm{Ra}$ & $\mathrm{Rz}$ & $\mathrm{Ra}$ & $\mathrm{Rz}$ \\
\hline $\mathrm{R}^{2} \%$ & 0.9829 & 0.9851 & 0.5657 & 0.4124 & 0.6640 & 0.6639 & 0.5804 & 0.2956 \\
\hline MSE & 0.00023 & 0.01199 & 0.00331 & 0.32601 & 0.00328 & 0.18777 & 0.00328 & 0.31881 \\
\hline
\end{tabular}

\begin{tabular}{|c|c|c|c|c|}
\hline \multicolumn{5}{|l|}{ SVR } \\
\hline \multirow{2}{*}{$\begin{array}{l}\text { Kernel } \\
\text { Data sets }\end{array}$} & \multicolumn{2}{|c|}{$\mathrm{RBF}$ kernel to predict $\mathrm{Ra}$} & \multicolumn{2}{|c|}{$\mathrm{RBF}$ kernel to predict $\mathrm{Rz}$} \\
\hline & Training dataset & Testing dataset & Training dataset & Testing dataset \\
\hline $\mathrm{R}^{2} \%$ & 0.9665 & 0.0576 & 0.9703 & 0.2239 \\
\hline adj. $R^{2} \%$ & 0.9653 & -107.7321 & 0.9696 & -4.4720 \\
\hline Mean error & -0.0017 & -0.0115 & -0.0136 & 0.0036 \\
\hline Mean absolute error & 0.0035 & 0.0897 & 0.0210 & 0.6469 \\
\hline Standard error & 0.0206 & 0.1223 & 0.1501 & 0.8809 \\
\hline MSE & 0.00042 & 0.0144 & 0.0225 & 0.7406 \\
\hline
\end{tabular}

Table 11 Details of best SVR models for prediction $\mathrm{Ra}$ and $\mathrm{Rz}$
Predicted $\mathrm{Ra}=\lambda_{a}-0.01022$ Tool Corner Radius

$$
+0.00944 \text { Tool Ra + 0.01744 Tool Rz }
$$

where $\lambda_{a}=$ Constant and it is equal to $0.4243,0.3125$, $0.3610,0.3438,0.4434$, and 0.4300 using Flat tool, and $\lambda_{a}=0.3084,0.1967,0.2452,0.2279,0.3275$, and 0.3141 using Hemispherical tool for Copper, Aluminum, Brass, Bronze, Polymer, and steel, respectively.

Predicted $\mathrm{Rz}=\lambda_{z}-0.15550$ Tool Radius +0.0037 Tool Ra +0.14866 Tool Rz 

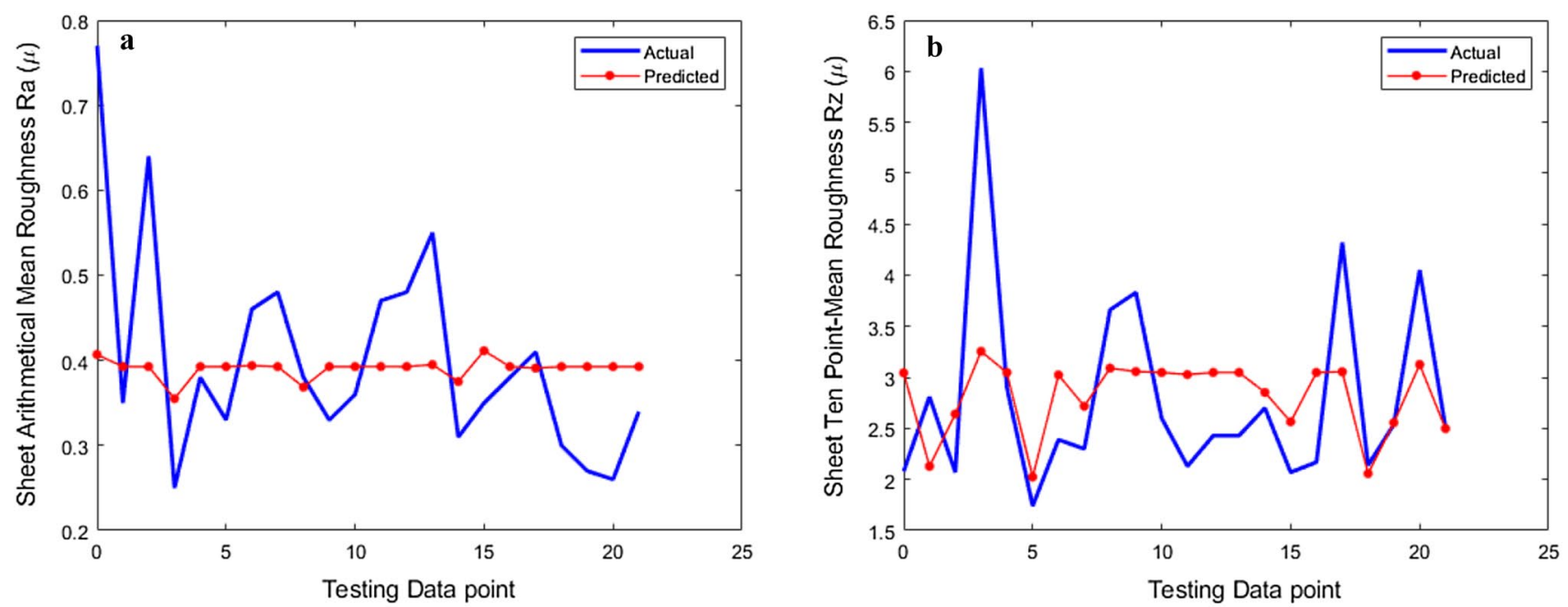

Fig. 9 Actual and predicted testing data via SVR where (a) shows Ra and (b) shows Rz

Table 12 Details of best two ANN models for prediction Ra and $\mathrm{Rz}$

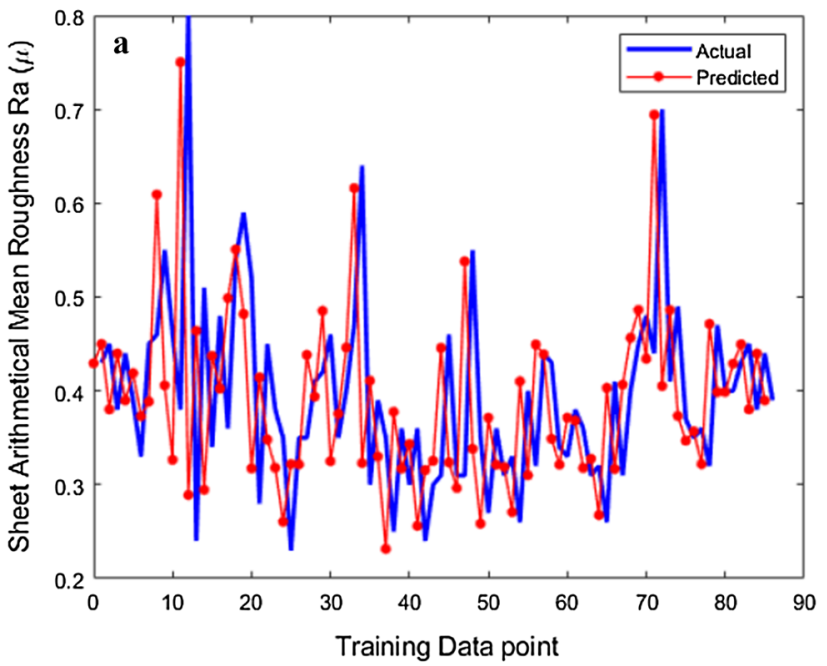

ANN with one output- Levenberg-Marquardt backpropagation (Trainlm)

\begin{tabular}{llllll}
\hline Transfer function & \multicolumn{2}{l}{ Softmax transfer function to predict $\mathrm{Ra}$} & & \multicolumn{2}{l}{$\begin{array}{l}\text { Logsig transfer function to predict } \\
\text { Rz }\end{array}$} \\
\cline { 2 - 3 } Data sets & Training dataset & Testing dataset & & Training dataset & Testing dataset \\
\hline $\mathrm{R}^{2} \%$ & 0.9231 & 0.9186 & & 0.9840 & 0.9509 \\
adj. $\mathrm{R}^{2} \%$ & 0.9124 & 0.9284 & & 0.9832 & 0.9599 \\
Mean error & -0.046 & 0.0103 & & -0.0121 & 0.1163 \\
Mean absolute error & 0.0194 & 0.0246 & & 0.0775 & 0.1630 \\
Standard error & 0.0269 & 0.0278 & & 0.1102 & 0.1831 \\
MSE & 0.00074 & 0.00084 & & 0.0122 & 0.0455 \\
\hline
\end{tabular}

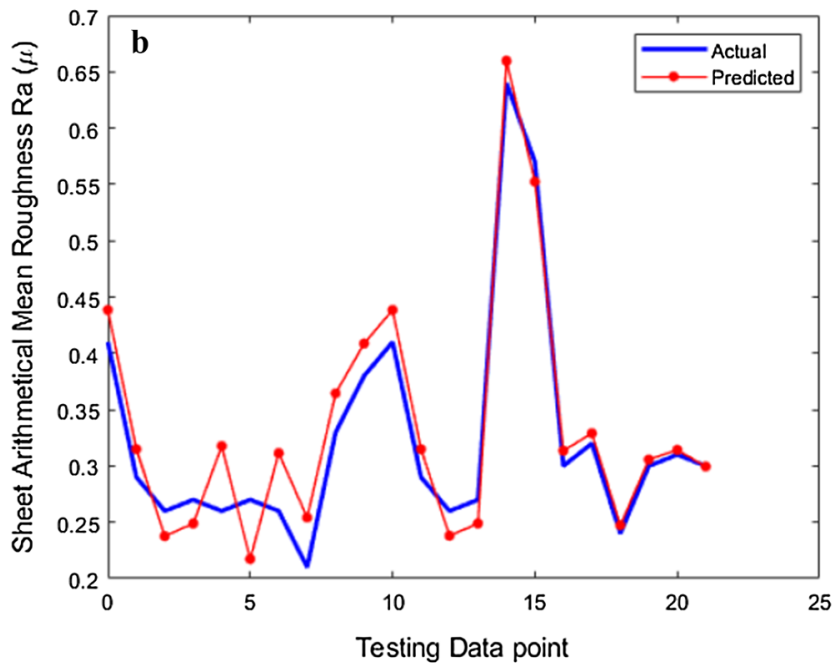

Fig. 10 Actual and predicted Ra via ANN (a) training data, (b) testing data 

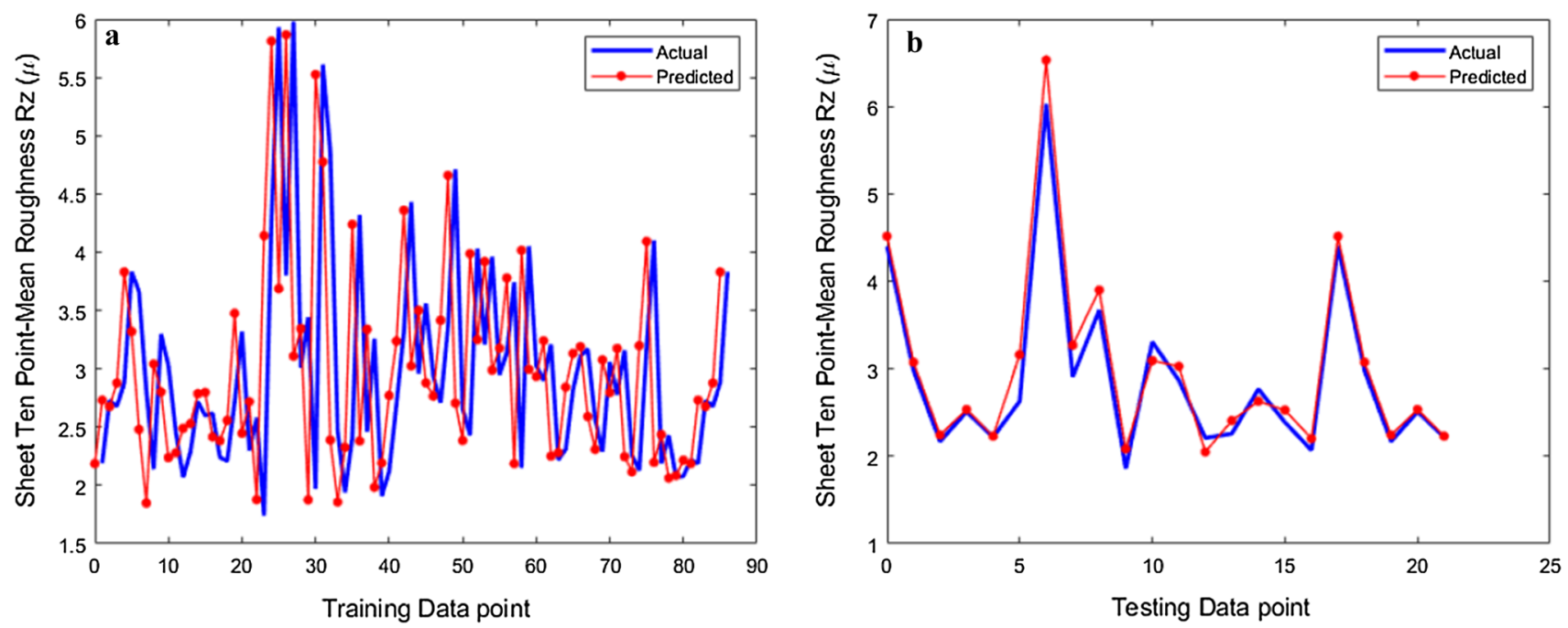

Fig. 11 Actual and predicted Rz via ANN (a) training data, (b) testing data

Fig. 12 "Important SPIF parameter" effect on the sheet surface roughness $\mathrm{Ra}$

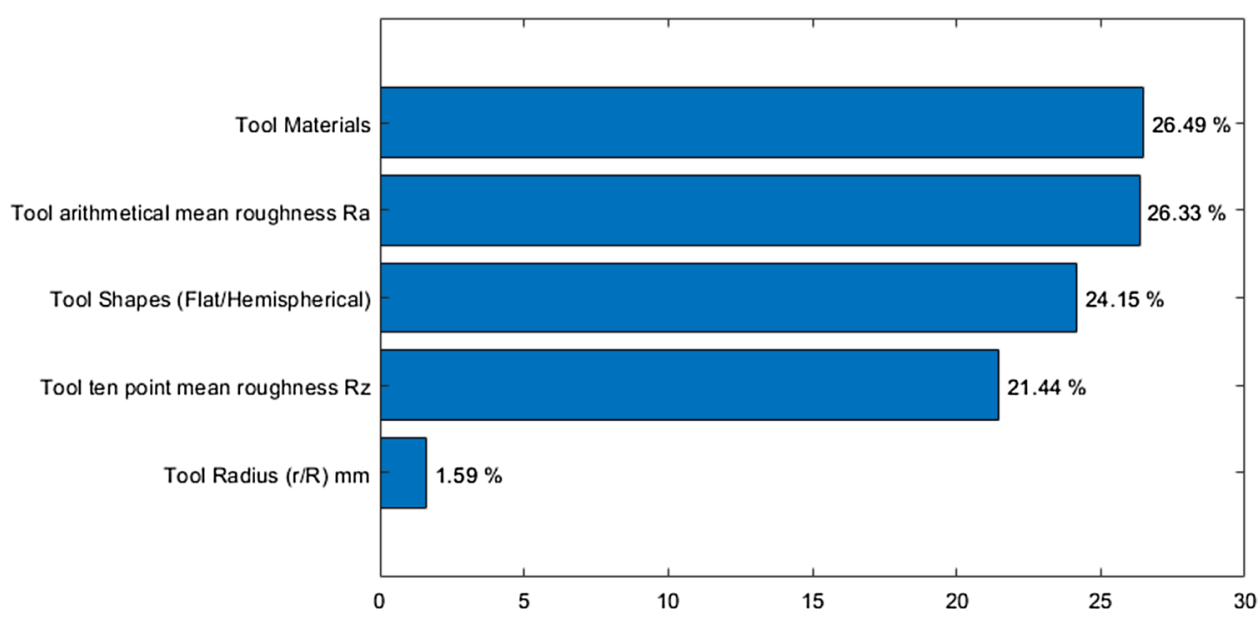

Predictor Effective Parameter on Sheet arithmetical mean roughness Ra of the Component

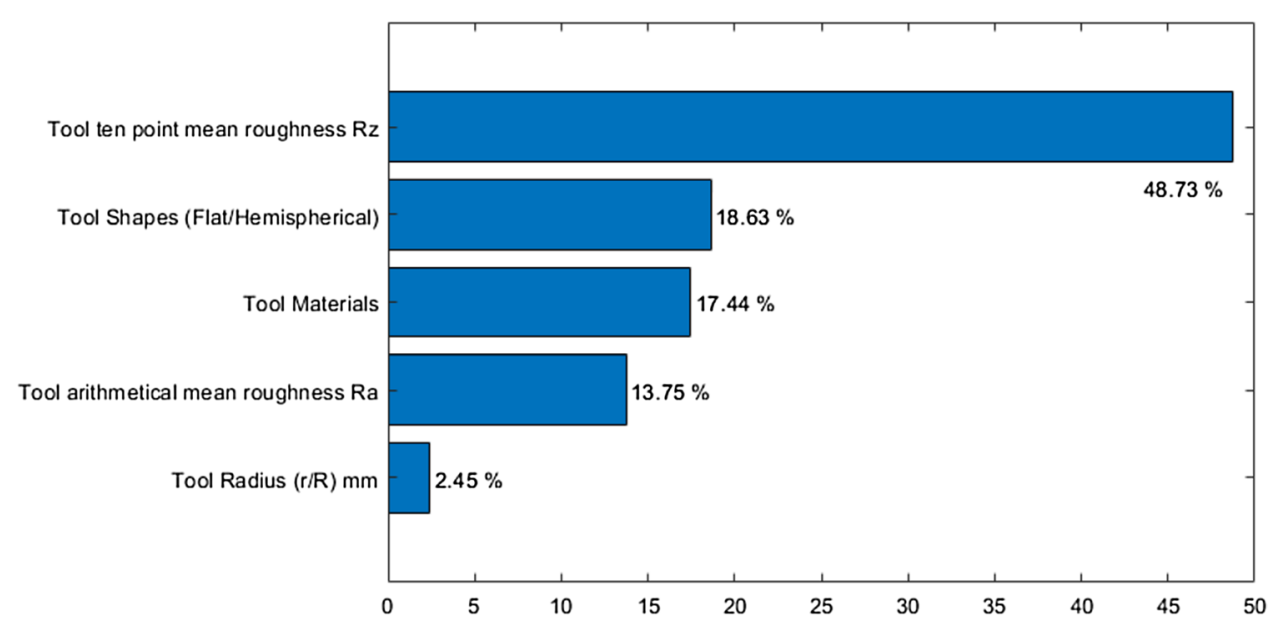

Predictor Effective Parameter on Sheet arithmetical mean roughness Rz of the Component
Fig. 13 "Important SPIF parameter" effect on the sheet surface roughness $\mathrm{Rz}$ 
where $\lambda_{z}=$ Constant and it is equal to $3.023,2.451,2.828$, $2.801,3.460$, and 3.289 using Flat tool, and $\lambda_{z}=2.118,1.546$, $1.923,1.896,2.555$, and 2.385 using Hemispherical tool for Copper, Aluminum, Brass, Bronze, Polymer, and steel, respectively.

The SPIF Parameters effected on the formed sheet surface roughness ( $\mathrm{Ra}$ and $\mathrm{Rz}$ ) are classified using Boosted Decision Trees. The classification is based on the importance of the parameter that fluctuates the result of the surface roughness. Figure 12 shows that the most important SPIF parameters effect on the sheet surface roughness $\mathrm{Ra}$ is the tool material and the tool surface roughness Ra. Figure 13 shows that the tool surface roughness Rz has the most significant effect on the sheet surface roughness Rz. Changing the tool radius has the lowest effect on both sheet surface roughness (Ra and $\mathrm{Rz}$ ).

In fact, that the tools have been created by a turning machine in the same machining conditions, but as mentioned in section 2, different materials with different hardness have been used to create the tools. Due to that, tools surface roughness is different, and the friction of various tools with different roughness values causes an effect on the surface roughness of the final products that have been formed by SPIF. E. Hagan and J. Jeswiet [36] analyzed the influence of several forming variables, such as step-down size and spindle speed, on surface roughness in the ISF process. They found that the large-scale wavy type surface finishes produced by tool path and large surface strains have caused the small-scale roughness type. Also, they claimed that tool hardness and its polished surface affect depth increment tests, and as a result, impact on the final product surface roughness.

The reasons, as mentioned earlier, make the tool materials to have the most significant value as predictor importance on the surface roughness $\mathrm{Ra}$ as shown in Fig. 12. Tool surface roughness $\mathrm{Ra}$, which is also one of the surface roughness parameters, has recorded high value as an important predictor affecting sheet $\mathrm{Ra}$. Ten-point mean roughness $(\mathrm{Rz})$ is the important parameter as his effect on sheet surface roughness Rz. Since the difference between the highest peak and the most in-depth "valley" on the surface is Rz, tool surface roughness $\mathrm{Rz}$ is cultivating the sheet surface and creating new grooves continuously. Therefore, it has such high importance as a predictor on the sheet surface roughness $\mathrm{Rz}$ as shown in Fig. 13. In other words, the asperities on the sheet surface (peaks) are destroyed and recreated continuously by the asperities of the tool. Finally, the tool shapes have been in the third and second order as important predictor parameters on $\mathrm{Ra}$ and $\mathrm{Rz}$, respectively, because the tool shapes have in our experiments only two alternative parameters (flat or hemispherical).

\section{Conclusion}

In this study, the examination of the SPIF parameters on the formed parts surface roughness $\mathrm{Ra}$ and $\mathrm{Rz}$ was performed experimentally by using AlMn $1 \mathrm{Mg} 1$ sheets with $0.22 \mathrm{~mm}$ initial thickness. The obtained actual data have been used to train and test different ANN structures and SVR with different kernels. The results showed that ANN gives a better result than SVR. Furthermore, ANN with one argument in the output predicted outcome sufficiently than two arguments structure. Trainlm training function has an effective rule in prediction than Traincgb and Trainrp. The $\mathrm{R}^{2}$ values of Softmax and logsig transfer function proved better results than others, $\mathrm{R}^{2}$ obtained from predicted $\left(\mathrm{R}^{2}=0.9628\right.$ for $\mathrm{Ra}$ and $\mathrm{R}^{2}=0.9972$ for $\mathrm{Rz}$ ). The tool materials and tool geometry are not equally affected on the surface roughness. Tools with different materials have different hardness, causing different surface strains. This is also true for the tool geometry, however, in the case of two tools with the same geometry but with different materials, forming will result in different surface strains, consequently different surface roughness. The second significant finding was that tool materials, and tool surface roughness $(\mathrm{Ra})$, emerged as the effective parameters in predictors of sheet surface (in terms of $\mathrm{Ra}$ ) with a rate of $26.49 \%$ and $26.33 \%$, respectively. While the prediction of the sheet surface roughness $(\mathrm{Rz})$ has shown that tool surface roughness $(\mathrm{Rz})$ has a significant effect on the outcome with the rate of $48.73 \%$. The high rate of $\mathrm{Rz}$ as a predictor is due to the asperities of the sheet surface that have been destroyed and recreated by the tool tip's asperities. Consequently, this shows the importance of the selection of the right tool in terms of material and surface quality. Finally, based on the actual dataset, two equations have been determined to predict the sheet surface roughness ( $\mathrm{Ra}$ and $\mathrm{Rz}$ ) analytically. The equations are for six different materials (Copper, Aluminum, Brass, Bronze, Polymer and Steel) and two different shapes of the tool (Flat and Hemispherical).

However, several limitations to this study need to be acknowledged. The sample size could be considered as small, and the results might be used only with caution, but to collect more data, numerous experiments need to be executed. Taken into account that these results can not be generalized unless adopting the same forming conditions, but it can provide researchers with a systematic insight into the influence of SPIF parameters on the surface roughness. The results can be widely utilized for further study, to control, and to predict the surface finish. Further data collection is required to determine precisely how the process parameters affect the forming process in different conditions. 


\section{Recommendations for further research work}

This research has thrown up many questions in need of further investigation. It is worth to study the effect of the examined parameters on sheets with different materials and thicknesses. It would be interesting to know whether the mechanical properties of the forming tool affect the product finishing or not. Furthermore, research needs to examine more closely the links between forming parameters and formed components.

Acknowledgement The research reported in this paper was supported by the Higher Education Excellence Program of the Ministry of Human Capacities in the frame of the Nanotechnology research area of Budapest University of Technology and Economics (BME FIKP-NANO) and by the GINOP-2.3.2-15-2016-00002 grant, together with the help of the TEMPUS Public Foundation and Stipendium Hungaricum Scholarship.

Funding Open access funding provided by Budapest University of Technology and Economics.

Open Access This article is licensed under a Creative Commons Attribution 4.0 International License, which permits use, sharing, adaptation, distribution and reproduction in any medium or format, as long as you give appropriate credit to the original author(s) and the source, provide a link to the Creative Commons licence, and indicate if changes were made. The images or other third party material in this article are included in the article's Creative Commons licence, unless indicated otherwise in a credit line to the material. If material is not included in the article's Creative Commons licence and your intended use is not permitted by statutory regulation or exceeds the permitted use, you will need to obtain permission directly from the copyright holder. To view a copy of this licence, visit http://creativecommons.org/licenses/by/4.0/.

\section{References}

1. Behera, A. K., de Sousa, R. A., Ingarao, G., \& Oleksik, V. (2017, June). Single point incremental forming: An assessment of the progress and technology trends from 2005 to 2015. Journal of Manufacturing Processes, 27, 37-62. https://doi.org/10.1016/j. jmapro.2017.03.014.

2. Reddy, N. V., \& Lingam, R. (2018, July). Double sided incremental forming: Capabilities and challenges. Journal of Physics Conference Series, 1063, 012170. https://doi.org/10.1088/17426596/1063/1/012170.

3. Li, Y., et al. (2017, September). A review on the recent development of incremental sheet-forming process. International Journal of Advanced Manufacturing Technology, 92(5-8), 2439-2462. https://doi.org/10.1007/s00170-017-0251-z.

4. Emmens, W. C., Sebastiani, G., \& van den Boogaard, A. H. (2010, June). The technology of Incremental Sheet FormingA brief review of the history. Journal of Materials Processing Technology, 210(8), 981-997. https://doi.org/10.1016/j.jmatprotec .2010.02.014.

5. Shrivastava, P., \& Tandon, P. (2019, April). Microstructure and texture based analysis of forming behavior and deformation mechanism of AA1050 sheet during Single Point Incremental Forming.
Journal of Materials Processing Technology, 266, 292-310. https ://doi.org/10.1016/j.jmatprotec.2018.11.012.

6. Wu, S. H., Reis, A., Andrade Pires, F. M., Santos, A. D., \& Barata da Rocha, A. (2012, February). Study of tool trajectory in incremental forming. Advances in Materials Research, 472475, 1586-1591. https://doi.org/10.4028/www.scientific.net/ AMR.472-475.1586.

7. Singh, S. (2017). A review on computer aided manufacturing factors affecting reduction of surface roughness and thickness. International Research Journal of Engineering and Technology, 4(7), 1474-1478 Retrieved from https://irjet.net/archives/V4/i7/ IRJET-V4I7314.pdf.

8. Bagudanch, I., Sabater, M., \& Garcia-Romeu, M. L. (2017, January). Single point versus two point incremental forming of thermoplastic materials. Advanced Materials and Technologies, 3(1), 135-144. https://doi.org/10.1080/2374068X.2016.1250245.

9. Mulay, A., Ben, B. S., Ismail, S., Kocanda, A., \& Jasiński, C. (2018, September). Performance evaluation of high-speed incremental sheet forming technology for AA5754 H22 aluminum and DC0 4 steel sheets. Archives of Civil and Mechanical Engineering, 18(4), 1275-1287. https://doi.org/10.1016/j.acme.2018.03.004.

10. Gulati, V., Aryal, A., Katyal, P., \& Goswami, A. (2016, April). Process parameters optimization in single point incremental forming. Journal of The Institution of Engineers: Series A, 97(2), 185-193. https://doi.org/10.1007/s40032-015-0203-z.

11. Nama, S. A., Namer, N. S. M., \& Najm, S. M. (2014). The effect of using grease on the surface roughness of Aluminum 1100 sheet during the Single Point Incremental Forming Process. Trends in Machine Design, 1(1), 53-56 Retrieved from www. stmjournals.com.

12. Rattanachan, K., \& Chungchoo, C. (2009). Formability in single point incremental forming of Dome Geometry. Asian International Journal of Science and Technology in Production and Manufacturing Engineering, 2(4), 57-63.

13. Nimbalkar, D. H., \& Nandedkar, V. M. (2013). Review of incremental forming of sheet metal components. International Journal of Engineering Research and Applications, 3(5), 39-51.

14. Khalil, U., Aziz, H., Jahanzaib, M., Ahmad, W., Hussain, S., \& Hafeez, F. (2018, September). Effects of forming tools and process parameters on surface roughness in Incremental Sheet Forming: A review. Advances in Science and Technology Research Journal, 12(3), 75-95. https://doi.org/10.12913/22998 $624 / 90223$.

15. Amirjan, M., Khorsand, H., Siadati, M. H., \& Eslami Farsani, R. (2013, October). Artificial Neural Network prediction of $\mathrm{Cu}-$ A12O3 composite properties prepared by powder metallurgy method. Journal of Materials Research and Technology, 2(4), 351-355. https://doi.org/10.1016/j.jmrt.2013.08.001.

16. Zain, A. M., Haron, H., \& Sharif, S. (2010, March). Prediction of surface roughness in the end milling machining using Artificial Neural Network. Expert Systems with Applications, 37(2), 1755-1768. https://doi.org/10.1016/j.eswa.2009.07.033.

17. Ezugwu, E. O., Fadare, D. A., Bonney, J., Da Silva, R. B., \& Sales, W. F. (2005, October). Modelling the correlation between cutting and process parameters in high-speed machining of Inconel 718 alloy using an artificial neural network. International Journal of Machine Tools and Manufacture, 45(12-13), 1375-1385. https:// doi.org/10.1016/j.ijmachtools.2005.02.004.

18. Hussaini, S. M., Singh, S. K., \& Gupta, A. K. (2014, January). Experimental and numerical investigation of formability for austenitic stainless steel 316 at elevated temperatures. Journal of Materials Research and Technology, 3(1), 17-24. https://doi. org/10.1016/j.jmrt.2013.10.010.

19. Li, E. (2013, March). Reduction of springback by intelligent sampling-based LSSVR metamodel-based optimization. 
International Journal of Material Forming, 6(1), 103-114. https ://doi.org/10.1007/s12289-011-1076-1.

20. Kondayya, D., \& Gopala Krishna, A. (2013, March). An integrated evolutionary approach for modelling and optimization of laser beam cutting process. International Journal of Advanced Manufacturing Technology, 65(1-4), 259-274. https://doi. org/10.1007/s00170-012-4165-5.

21. Marouani, H., \& Aguir, H. (2012, June). Identification of material parameters of the Gurson-Tvergaard-Needleman damage law by combined experimental, numerical sheet metal blanking techniques and artificial neural networks approach. International Journal of Material Forming, 5(2), 147-155. https://doi.org/10.1007/ s12289-011-1035-x.

22. Lela, B., Bajić, D., \& Jozić, S. (2009, June). Regression analysis, support vector machines, and Bayesian neural network approaches to modeling surface roughness in face milling. International Journal of Advanced Manufacturing Technology, 42(11-12), 10821088. https://doi.org/10.1007/s00170-008-1678-z.

23. Ning, J., Nguyen, V., Huang, Y., Hartwig, K. T., \& Liang, S. Y. (2018, November). Inverse determination of Johnson-Cook model constants of ultra-fine-grained titanium based on chip formation model and iterative gradient search. International Journal of Advanced Manufacturing Technology, 99(5-8), 1131-1140. https ://doi.org/10.1007/s00170-018-2508-6.

24. Ning, J., \& Liang, S. Y. (2019, June). Inverse identification of Johnson-Cook material constants based on modified chip formation model and iterative gradient search using temperature and force measurements. International Journal of Advanced Manufacturing Technology, 102(9-12), 2865-2876. https://doi. org/10.1007/s00170-019-03286-0.

25. Zuo, K.-T., Chen, L.-P., Zhang, Y.-Q., \& Yang, J. (2006, January). Manufacturing- and machining-based topology optimization. International Journal of Advanced Manufacturing Technology, 27(5-6), 531-536. https://doi.org/10.1007/s00170-004-2210-8.

26. Maji, K., \& Kumar, G. (2020, March). Inverse analysis and multi-objective optimization of single-point incremental forming of AA5083 aluminum alloy sheet. Soft Computing, 24(6), 4505-4521. https://doi.org/10.1007/s00500-019-04211-z.

27. Kurra, S., Hifzur Rahman, N., Regalla, S. P., \& Gupta, A. K. (2015, July). Modeling and optimization of surface roughness in single point incremental forming process. Journal of Materials Research and Technology, 4(3), 304-313. https://doi. org/10.1016/j.jmrt.2015.01.003.

28. Oraon, M., \& Sharma, V. (2018). Prediction of surface roughness in single point incremental forming of AA3003-O alloy using artificial neural network. International Journal of Materials Engineering Innovation, 9(1), 1. https://doi.org/10.1504/IJMAT EI.2018.092181.

29. Radu, C., Cristea, I., Herghelegiu, E., \& Tabacu, S. (2013, July). Improving the accuracy of parts manufactured by single point incremental forming. Applied Mechanics and Materials, 332, 443-448. https://doi.org/10.4028/www.scientific.net/ AMM.332.443.

30. Mulay, A., Ben, B. S., Ismail, S., \& Kocanda, A. (2019, August). Prediction of average surface roughness and formability in single point incremental forming using artificial neural network. Archives of Civil and Mechanical Engineering, 19(4), 1135-1149. https://doi.org/10.1016/j.acme.2019.06.004.

31. Oraon, M., Sharma, V., \& Mandal, S. (2020). Performance measurement in incremental deformation of Brass Cu67Zn33 through soft computing tool (pp. 83-89).

32. Pedregosa, F., et al. (2011). Scikit-learn: Machine Learning in $\{P\}$ ython. Journal of Machine Learning Research, 12, 2825-2830 Retrieved from https://scikit-learn.org/stable/about.html\#citin g-scikit-learn.
33. Zhang, G., Eddy Patuwo, B., \& Hu, M. Y. (1998). Forecasting with artificial neural networks: The state of the art. International Journal of Forecasting, 14(1), 35-62 Retrieved from https://econp apers.repec.org/RePEc:eee:intfor:v:14:y:1998:i:1:p:35-62.

34. Parrella, F. (2007). Online support vector regression online support vector machines for regression. Science (80-), June, 101.

35. Mathworks, C. (2015). Statistics and Machine Learning Toolbox ${ }^{\mathrm{TM}}$ User' s Guide R 2015 b.

36. Hagan, E., \& Jeswiet, J. (2004, October). Analysis of surface roughness for parts formed by computer numerical controlled incremental forming. Journal of Engineering Manufacture, Proceedings of the Institution of Mechanical Engineers Part B, 218(10), 1307-1312. https://doi.org/10.1243/095440504232355 9.

Publisher's Note Springer Nature remains neutral with regard to jurisdictional claims in published maps and institutional affiliations

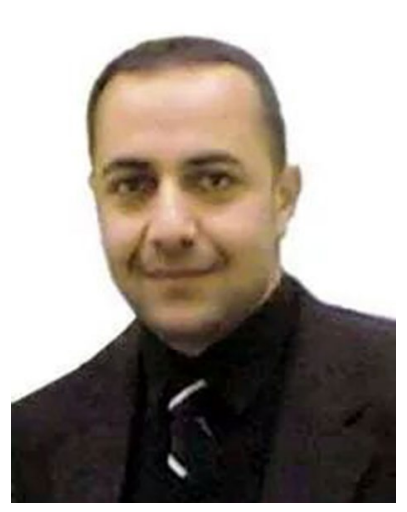

Sherwan Mohammed Najm is Assistant Lecturer at Kirkuk Technical InstitutelNorthern Technical University, Mosul, IQ. He received his B.S.c and MSc in Mechanical Engineering at the Technical Engineering College / Baghdad / Engineering of Mould and Equipment techniques Department in 2006 and 2014, respectively. He is also a member of the Republic of Iraq Ministry of Higher Education and Scientific Research: Baghdad, IQ, as well as a member of the Iraqi Engineers Union and Kurdistan Engineers Union. His main research interests are in Incremental Sheet Forming, smart manufacturing, ANN. Currently, he is a doctoral candidate in the research stage at the Budapest University of Technology and Economics (BME).

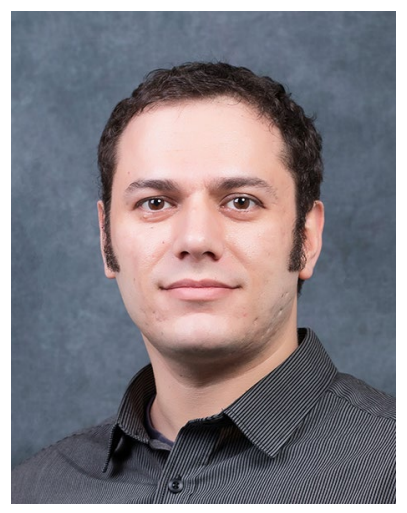

Imre Paniti is a Research Fellow at the Institute for Computer Science and Control, Research Laboratory on Engineering \& Management Intelligence, and a researcher at the Research Center of Vehicle Industry, Széchenyi István University. He received both his MSc in Mechanical Engineering and $\mathrm{PhD}$ at the Budapest University of Technology and Economics (BME) in 2007 and 2015, respectively. He is also a supervisor at the BME, Doctoral School of Mechanical Engineering, Department of Manufacturing Engineering, as well as a public board member of the Hungarian Academy of Sciences. His main research interests are in Incremental Sheet Forming, smart manufacturing, Human-Robot Collaboration, digital twins, and cyber-physical systems. 